\title{
Numerical Investigation of the Effect of Nanoparticle Diameter and Sphericity on the Thermal Performance of Geothermal Heat Exchanger Using Nanofluid as Heat Transfer Fluid
}

\author{
Ruiqing Du ${ }^{1,2}$, Dandan Jiang ${ }^{1,2}$ and Yong Wang ${ }^{1,2, *}$ \\ 1 National Centre for International Research of Low-carbon and Green Buildings, Ministry of Science \& \\ Technology, Chongqing University, Chongqing 400045, China; drq20171702044t@163.com (R.D.); \\ 201717131104@cqu.edu.cn (D.J.) \\ 2 Joint International Research Laboratory of Green Buildings and Built Environments, Ministry of Education, \\ Chongqing University, Chongqing 400045, China \\ * Correspondence: cqwangyong@cqu.edu.cn; Tel.: +86-023-65127185
}

Received: 25 February 2020; Accepted: 26 March 2020; Published: 2 April 2020

check for updates

\begin{abstract}
The geothermal heat exchanger system is one of the most energy-efficient and environmentally friendly building service systems. In the present study, $\mathrm{CuO} /$ water nanofluid was used as the heat transfer fluid to enhance the energy efficiency of the geothermal heat exchangers. A three-dimensional numerical model was employed to investigate the effect of nanoparticle diameter and sphericity on the thermal performance of the geothermal heat exchanger, and it was well validated against the experimental results of nanofluids in the geothermal heat exchangers. The numerical results showed that nanoparticles with a diameter of $5 \mathrm{~nm}$ and $50 \mathrm{~nm}$ were not recommended for the nanofluids used in the geothermal heat exchangers due to the performance efficiency coefficient lower than 1, and the optimum diameter was $40 \mathrm{~nm}$, which had the highest performance efficiency coefficient (1.004875). Moreover, the spherical particle-based nanofluid was characterized by the $8.55 \%$ higher energy efficiency, in comparison to rod-shaped particle-based nanofluid. Therefore, the application of nanofluid in the geothermal heat exchanger can enhance heat transfer, and the proposed optimum particle diameter and sphericity could contribute to higher energy efficiency.
\end{abstract}

Keywords: nanofluid; particle diameter; particle sphericity; geothermal heat exchanger

\section{Introduction}

The global energy crisis and environmental problems motivate the world to find renewable energy such as geothermal energy. The ground-source heat pump (GSHP) systems that employed shallow geothermal energy for building heating and cooling have been widely used all over the world [1]. The geothermal heat exchanger (GHE) is the main component in the GSHP system, and it plays a significant role in the energy efficiency and lower running cost of the GSHP system [2]. Thus, it is of great significance to improve the thermal performance of GHE.

To enhance the heat transfer rate of heat exchangers, nanofluids with a higher thermal conductivity than the base fluids can be introduced in heat exchangers as a heat transfer medium [3]. Numerous studies have investigated the thermal performance of heat exchangers using nanofluids. Kumar et al. [4] reviewed the studies about applying nanofluids in plate heat exchangers (PHEs). The results suggested that $\mathrm{CuO}$-based nanofluids can contribute to a $60 \%$ enhancement in the heat transfer rate of PHEs. However, two factors were limiting the wider use of nanofluid for the higher pumping power and the higher cost. Wilk et al. [5] found that $\mathrm{Cu}$ nanofluid can enhance the heat transfer processes of coil 
heat exchangers even at low volume concentration $(0.011 \%)$ due to the higher thermal conductivity. Nasir et al. [6] experimentally used the nanofluid in a compact heat exchanger and investigated its heat transfer rate. The results showed that, after adding the $2 \mathrm{vol} \% \mathrm{CuO}$ nanoparticles into the water, the heat transfer rate and convection heat transfer coefficient increased by $17.3 \%$ and $40 \%$, respectively. Said et al. [7] conducted an experimental investigation on the heat transfer enhancement of a shell-and-tube heat exchanger using $\mathrm{CuO} /$ water nanofluid. They found that the overall heat transfer coefficient and convective heat transfer increased by $7 \%$ and $11.39 \%$, respectively. Moreover, the friction factor increased by $2 \%$ for the $0.05 \mathrm{vol} \% \mathrm{CuO} /$ water nanofluid. Karuppasamy et al. [8] numerically investigated the heat transfer of $\mathrm{CuO}$ nanofluid in a cone-shaped inserted heat exchanger tube. The results showed that the pressure drop increased along the tube due to the collision between nanoparticles and the insert wall. Rao et al. [9] experimentally investigated the heat transfer and friction factor of $\mathrm{CuO}$ nanofluid in a double pipe U-bend heat exchanger. They found a maximum Nusselt number enhancement of $18.6 \%$ and a pressure drop increase of $9.2 \%$ for the $0.06 \%$ particle loading. According to the above literature, with a good thermal performance in other types of heat exchangers, the $\mathrm{CuO} /$ water nanofluid may also contribute to the heat transfer enhancement of GHE, while it may cause a larger pressure drop and pumping power consumption.

The GHEs using nanofluids as circuit fluid have been investigated in recent years. Narei et al. [10] studied the effect of using nanofluid on bore length reduction of a vertical GHE. They found that nanofluid contributed to a reduction of $1.3 \%$ in the required bore length. Diglio et al. [11] conducted a numerical investigation to find the best nanofluid that achieved the lowest thermal resistance and minimum pressure drop of the borehole. They found that the thermal resistance of borehole had a reduction of 3.8\%, while the pressure drop had an increase of $6 \%$ when Cu-based nanofluid (volumetric concentration $=0.1 \%$ ) was applied in GHEs. Dan Sui et al. [12] numerically investigated the energy extraction capability of the geothermal double pipe heat exchanger using $\mathrm{Al}_{2} \mathrm{O}_{3}$ nanofluid as heat transfer fluid. The nanofluid was found to extract $11.24 \%$ more energy than the base fluid. Sergio Bobbo et al. [13] calculated the Mouromtseff number of $\mathrm{Al}_{2} \mathrm{O}_{3} /$ water nanofluid for four concentrations for the geothermal application. The results showed that the nanofluid of $\mathrm{W} 4403 \mathrm{wt} \%$ can be efficiently used in the geothermal system. Mahdi Daneshipour et al [14]. compared the $\mathrm{CuO} /$ water and $\mathrm{Al}_{2} \mathrm{O}_{3} /$ water nanofluid applied for the thermal performance of GHE. They found the $\mathrm{CuO} /$ water nanofluid was characterized by a higher heat transfer rate and higher pressure drop, in comparison to that of alumina-water nanofluid. Baran et al. [15] numerically investigated the effect of $\mathrm{Al}_{2} \mathrm{O}_{3} /$ water nanofluid on the thermal performance of a multitubular heat exchanger buried in the ground. They found an increase in the convective heat transfer coefficient of nanofluid compared to water when the volume concentration was $1 \%$. Kapicioglu et al. [16] used the $\mathrm{Al}_{2} \mathrm{O}_{3}$ /ethylene glycol-water nanofluid in GHEs. The results showed that the coefficient of performance (COP) of U-type GHE and spiral GHE had a 2.5\% and $3 \%$ increase after the $0.1 \mathrm{vol} \%$ nanofluid was used as heat transfer fluid, respectively. Meanwhile, the higher volume concentration $(0.2 \%)$ did not cause any performance increase.

The nanoparticle diameter and sphericity play a significant role in the thermal conductivity and viscosity of nanofluid [17]. Numerous efforts have focused on the effects of particle diameter and sphericity on the thermal performance of heat exchangers using nanofluid as heat transfer fluid. Jamshidi et al. [18] numerically investigated the effects of nanoparticle diameter on the energy extraction capability of finned conical helical GHE. The results showed that the heat transfer coefficient decreased when the nanoparticle diameter increased. Elias et al. [19] analyzed the effect of different particle sphericity on the heat transfer characteristics of a shell and tube heat exchanger. They found cylindrical nanoparticles owned the best performance in terms of thermal conductivity, heat transfer coefficients, and heat transfer rate. Vanaki et al. [20] numerically investigated the effect of $\mathrm{SiO}_{2}$ nanoparticle shape on the heat transfer of wall channels. The results showed that platelets nanoparticle had the highest heat transfer rate. Mahian et al. [21] investigated the effect of nanoparticle shape on the performance of the solar collector. They found that a brick shape achieved the minimum entropy generation in copper tubes. Arani et al. [22] experimentally investigated the effect of $\mathrm{TiO}_{2}$ nanoparticle diameter $(10 \mathrm{~nm}$, 
$20 \mathrm{~nm}, 30 \mathrm{~nm}$, and $50 \mathrm{~nm}$ ) on the pressure drop and thermal performance of nanofluid in a tube heat exchanger. The results showed that $20 \mathrm{~nm}$ nanoparticles had a higher thermal performance factor. Anoop et al. [23] found $45 \mathrm{~nm} \mathrm{Al}_{2} \mathrm{O}_{3}$ particles were characterized by a higher heat transfer coefficient than $150 \mathrm{~nm}$ particles in tube flow. Ji et al. [24] studied the effect of different nominal particle diameters $(50 \mathrm{~nm}, 80 \mathrm{~nm}, 2.2 \mu \mathrm{m}$, and $20 \mu \mathrm{m}$ ) on the heat transfer performance of a heat pipe. They found $80 \mathrm{~nm}$ nanoparticles had the best heat transfer performance. Alsarraf et al. [25] numerically investigated the effect of nanoparticle shape on the thermal performance of alumina nanofluid in a mini channel heat exchanger. They found the platelet nanoparticle had the highest heat transfer rate and pumping power, while the least values of these parameters belonged to the spherical nanoparticle. Al-Rashed et al. [26] numerically investigated the effect of nanoparticle shape on the thermal performance of a double-pipe heat exchanger. They also found that the spherical nanoparticle had the minimum frictional entropy generation rate, thermal entropy generation rate and total entropy generation rate. Bahiraei et al. [27] investigated the thermal performance of nanofluid in a rectangular channel fitted with the conical ribs for the different particle shapes. They found that the oblate-spheroid-shaped nanoparticles owned the highest thermal entropy generation followed by the brick, blade, cylinder, and platelet-shaped nanoparticles.

Although a few researchers have numerically or analytically studied GHEs using nanofluids, to the knowledge of authors, there is no researcher using numerical models that are supported by experimental data of nanofluids in the GHEs. Moreover, there is no effort focusing on the effect of nanoparticle sphericity on the heat transfer of GHEs using nanofluids. Meanwhile, although Jamshidi et al. [18] studied the effect of nanoparticle diameter on the thermal performance of helical GHE, more investigations are necessary for the effect of nanoparticle diameter on the heat transfer of double U-tube GHE. Therefore, the present study is expected to fill the research gap.

In this study, the $\mathrm{CuO} /$ water nanofluid was experimentally used in the GHE, and the numerical model was validated against the data obtained from the experiment system, which had the same geometry with it for the first time. Furthermore, the numerical model was used to investigate the effect of nanoparticle diameter and sphericity on the pressure drop, heat transfer rate and energy efficiency of GHE. Moreover, almost all results of the previous studies showed that the lower nanoparticle diameter and sphericity had a better thermal performance of heat exchangers. However, in this study, the higher heat transfer rate and energy efficiency of GHE were found to belong to the higher particle diameter and sphericity, which were characterized by the lower viscosity of nanofluid. The results can contribute to the design of the GHE system using nanofluid as a circuit fluid and the enhancement of energy efficiency of GHSP systems.

\section{Numerical Study}

\subsection{Characterization of Material}

To investigate the thermal performance of nanofluid in GHE, the properties of material should be measured for both experimental and numerical investigation.

The TEM image of $\mathrm{CuO} /$ water nanofluid is shown in Figure 1. The nanofluids and the information of nanofluids were provided by Jingrui Research Nanomaterials, Inc. (Anhui, China). The concentration of $\mathrm{CuO} /$ water nanofluid was $3 \mathrm{wt} \%$, and the average diameter of nanoparticles was $23.26 \mathrm{~nm}$. The thermal conductivity and specific heat capacity of nanofluid were measured. A liquid thermal conductivity measuring instrument (LTCMI, TC3010, Xiaxi, Xian, China) was employed in measuring the thermal conductivity of nanofluid. The measuring range of the LTCMI was $0.001-5.0 \mathrm{~W} /(\mathrm{m} \bullet \mathrm{K})$ and the uncertainty was $\pm 2 \%$. Moreover, the specific heat meter (HC2000, Xiaxi, Xian, China) was used to measure the specific heat capacity of nanofluid. The measuring range of specific heat meter was -30 to $100^{\circ} \mathrm{C}$, and the uncertainty was $\pm 2 \%$. 


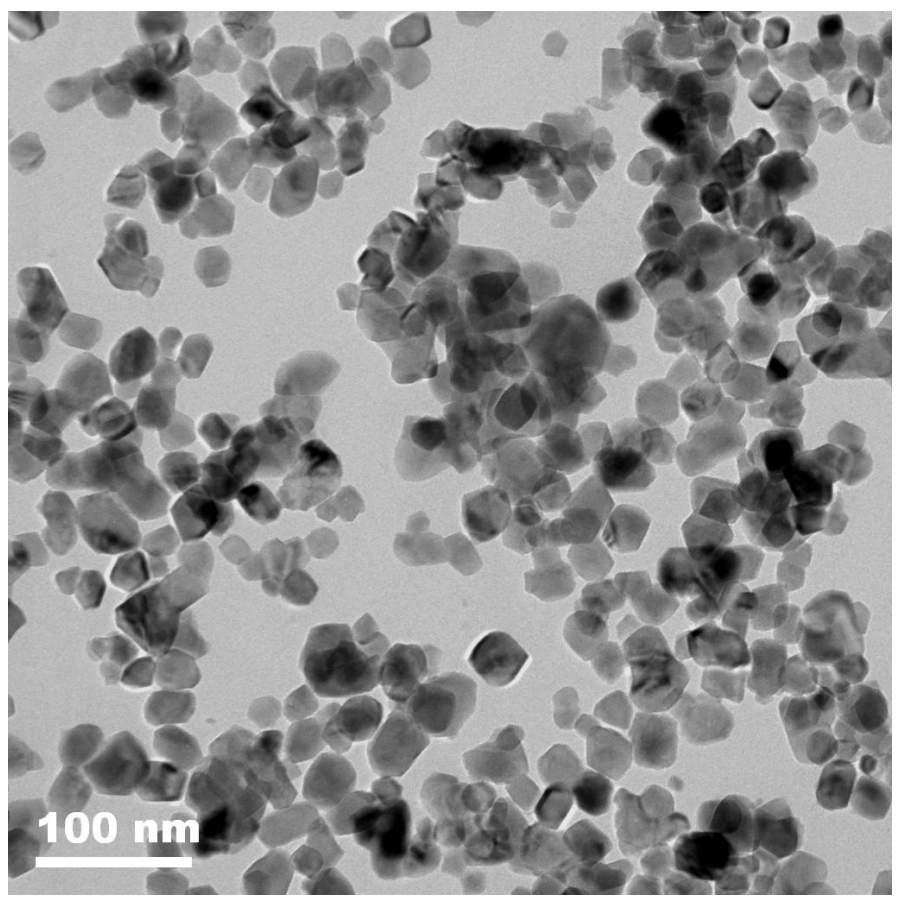

Figure 1. TEM image of $\mathrm{CuO}$ nanoparticles.

The thermophysical properties of $\mathrm{CuO} /$ water nanofluid are shown in Table 1. Similar results reported in the literature were observed for our studied nanofluid. Xuan et al. [28] experimentally investigated the thermal conductivity of $2.5 \mathrm{vol} \% \mathrm{Cu}$ nanofluid and found an enhancement of nearly $24 \%$ for the nanofluid with spherical particles. Said et al. [7] reported that the thermal conductivity of $\mathrm{CuO} /$ water nanofluid with $183.4 \mathrm{~nm}$ nanoparticles at $35^{\circ} \mathrm{C}$ was nearly $0.65 \mathrm{~W} / \mathrm{m} \bullet \mathrm{K}$ for the volume fraction of $0.05 \%$. Khedkar et al. [29] experimentally investigated the $\mathrm{CuO} /$ water nanofluid with 25 -nm-diameter nanoparticles and reported the thermal conductivity of nearly $0.62 \mathrm{~W} / \mathrm{m} \bullet \mathrm{K}$ for the volume fraction of 0.01. Eastman et al. [30] experimentally investigated the $\mathrm{CuO}$ nanofluid and reported a conductivity ratio of 1.1 for the volume fraction of 0.01. Meanwhile, Sezer et al. [31] and Khan et al. [17] reviewed the studies about the thermophysical properties of CuO-based nanofluids. The maximum discrepancy between the results of these studies and the present study is less than $5 \%$, which also validated the reasonability of the present results.

Table 1. The thermophysical properties of material.

\begin{tabular}{cccccc}
\hline Physical Parameters & CuO & Water & Sand & Copper Tube & CuO/Water Nanofluid \\
\hline Density, ${ }^{\rho},\left(\mathrm{kg} / \mathrm{m}^{3}\right)$ & 6500 & 995 & 1953.39 & 8978 & 0.6343 \\
Specific heat, ${ }_{p},(\mathrm{~J} / \mathrm{kg} \bullet \mathrm{K})$ & 540 & 4180 & 1348 & 381 & 4069.81 \\
Thermal conductivity, $k,(\mathrm{~W} / \mathrm{m} \bullet \mathrm{K})$ & 33 & 0.621 & 1.13 & 387.6 & 1026 \\
Dynamic viscosity, $\mu,(\mathrm{kg} / \mathrm{m} \bullet \mathrm{s})$ & $\backslash$ & 0.7659 & $\backslash$ & $\backslash$ & $\backslash$ \\
Grains size $\times 10^{-3}(\mathrm{~m})$ & $\backslash$ & $\backslash$ & $75-250$ & $\backslash$ & $\backslash$ \\
Average grains size $\times 10^{-3}(\mathrm{~m})$ & $\backslash$ & $\backslash$ & 83 & $\backslash$ & $\backslash$ \\
Porosity & $\backslash$ & $\backslash$ & $46 \%$ & $\backslash$ & $\backslash$ \\
Moisture & $\backslash$ & $\backslash$ & $10.1 \%$ & $\backslash$ & $\backslash$ \\
\hline
\end{tabular}

In addition, the thermophysical properties of the copper tube [32] and sand [33], as well as the grain size and moisture of sand [33], were obtained from our previous study and shown in Table 1.

\subsection{Numerical Model}

A three-dimensional model was built to investigate the effect of nanofluid on the thermal performance of GHEs, including a sandbox, a GHE inserted into the sandbox, and the sand filled in the 
sandbox representing the underground soil (Figure 2). The size of the sandbox was $0.8 \mathrm{~m} \times 0.25 \mathrm{~m}$ $\times 0.58 \mathrm{~m}$. The GHE was a copper double-U-tube for piping heat transfer fluid. The length and the inner diameter of the tube were $2 \mathrm{~m}$ and $0.01 \mathrm{~m}$, respectively. The thermal resistance of the copper tube wall was neglected in simulation because of its high thermal conductivity and the wall thickness of $0.001 \mathrm{~m}$. The boreholes were reasonably neglected using drill cuttings as the backfill material when the diameter of tubes was small [34].

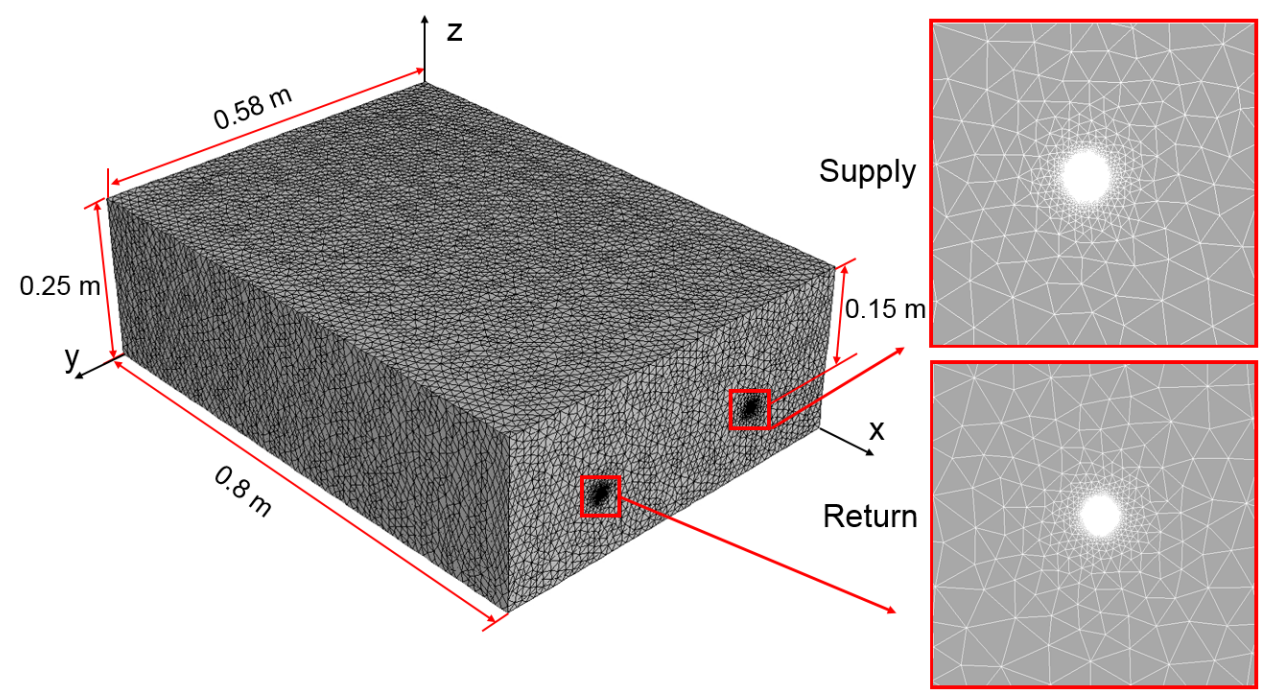

(a)

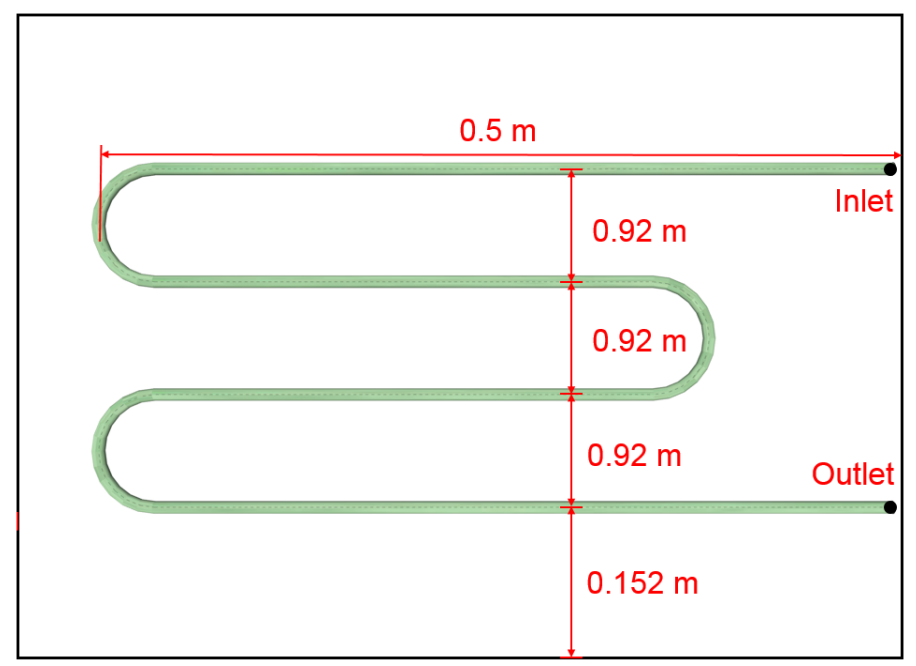

(b)

Figure 2. The geometry and the mesh results of numerical models: (a) The geometry of sandbox and mesh results; (b) The location and structure of heat exchanger.

According to the purpose of this study, the following governing equations were used to simulate the heat transfer of the nanofluid in the GHE:

To simplify the numerical simulation, the sand was assumed to be homogeneous media with certain porosities, which was quite common in the previous studies [33]. Meanwhile, the effects of moisture and porosity were considered though the measured thermophysical properties of sand, such as thermal conductivity and specific heat, which were inputted into the numerical model. For the 
heat transfer of sand without the moisture and porosity, only the thermal conduction is considered. Therefore, the heat transfer in the sand can be calculated by [33]:

$$
\frac{\partial T}{\partial t}=\frac{k_{\text {sand }}}{\rho_{\text {sand }} C_{p, \text { sand }}}\left(\frac{\partial^{2} T_{k}}{\partial x^{2}}+\frac{\partial^{2} T_{k}}{\partial y^{2}}+\frac{\partial^{2} T_{k}}{\partial z^{2}}\right),
$$

where $t$ is the time of the heat transfer process. $\mathrm{x}, \mathrm{y}$, and $\mathrm{z}$ are the $\mathrm{x}$-axis coordinates, $\mathrm{y}$-axis coordinates, and z-axis coordinates. $k_{\text {sand }}, C_{p \text {,sand }}$ and $\rho_{\text {sand }}$ represent the thermal conductivity, specific heat capacity and density of the sand.

Continuity equation of nanofluid [35]:

$$
\nabla \cdot\left(\rho_{f} u_{f}\right)=0,
$$

where $\rho_{f}$ is the density of the fluid, and $u_{f}$ is the flow rate.

Momentum equation of nanofluid [35]:

$$
\nabla \cdot\left(\rho_{f} u_{f} u_{f}\right)=-\nabla p+\nabla \cdot\left(\rho_{f} \nabla u_{f}\right)+\rho_{f} g,
$$

where $\rho_{f}$ is the density of the fluid, $u_{f}$ is the flow rate of fluid, $p$ is pressure, and $g$ is the gravitational acceleration.

Energy equation of nanofluid [35]:

$$
\nabla \cdot\left(\rho_{f} C_{p, f} T_{f} u_{f}\right)=\nabla \cdot\left(k_{f} \nabla T_{f}\right),
$$

where $\rho_{f}$ is the density of the fluid, $C_{p, f}$ is the specific heat of the fluid, $u_{f}$ is the flow rate of the fluid, $p$ is the pressure, $T_{f}$ is the temperature of the fluid, and $k_{f}$ is the thermal conductivity.

The effective viscosity of nanofluids for different nanoparticle diameter was obtained by the following equations [36]:

$$
\mu_{n f}=\mu_{b f}\left[1+2.5 \varphi_{e}+\left(2.5 \varphi_{e}\right)^{2}+\left(2.5 \varphi_{e}\right)^{3}+\left(2.5 \varphi_{e}\right)^{4}\right],
$$

where $\mu_{n f}$ is the viscosity of nanofluid, $\mu_{b f}$ is the viscosity of the base fluid, and $\varphi_{e}$ is the effective volume fraction.

In this study, the effective thermal conductivity of nanofluids for different nanoparticle diameters was calculated using a combined and dynamic model proposed by Murshed et al. [37]. The thermal conductivity of nanofluid was obtained by the following equations [37]:

$$
\begin{aligned}
k_{n f}= & \left\{k_{b f} \frac{\varphi_{p} \omega\left(k_{p}-\omega k_{b f}\right)\left[2 \gamma_{1}^{3}-\gamma+1\right]+\left(k_{p}+2 \omega k_{b f}\right) \gamma_{1}^{3}\left[\varphi_{p} \gamma^{3}(\omega-1)+1\right]}{\gamma_{1}^{3}\left(k_{p}+2 \omega k_{b f}\right)-\varphi_{p}\left(k_{p}-\omega k_{b f}\right)\left[\gamma_{1}^{3}-\gamma^{3}+1\right]}\right\} \\
& +\left\{\varphi_{p}^{2} \gamma^{6} k_{b f}\left(3 \Lambda^{2}+\frac{3 \Lambda^{2}}{4}+\frac{9 \Lambda^{3}}{16} \frac{k_{c p}+2 k_{b f}}{2 k_{c p}+3 k_{b f}}+\frac{3 \Lambda^{4}}{2^{6}}\right)\right\}+ \\
& +\left\{\frac{1}{2} \rho_{c p} c_{p-c p} d_{s}\left[\sqrt{\frac{3 k_{B} T\left(1-1.5 \gamma^{3} \varphi_{p}\right)}{2 \pi \rho_{c p} \gamma^{3} r_{p}^{3}}}+\frac{G_{T}}{6 \pi \mu \gamma r_{p} d_{s}}\right]\right\}
\end{aligned}
$$

where $k_{n f}$ is the effective thermal conductivity of nanofluid, $k_{b f}$ is the thermal conductivity of the base fluid, $\varphi_{p}$ is the particle volume fraction, $r_{p}$ is particle radius, $\omega=k_{l r} / k_{b f}$ is the empirical parameter, $\Lambda=\left(k_{c p}-k_{b f}\right) /\left(k_{c p}+2 k_{b f}\right), k_{c p}$ is the thermal conductivity of the complex particle, $d_{s}$ is the distance between two particles, $\rho_{c p}$ is the average density of the complex particle, $c_{p-c p}$ is the average specific heat of the complex particle, $k_{B}$ is the Boltzmann's constant, $G_{T}$ is the total interparticle potential, $\mu$ is the viscosity, and $\gamma_{1}=1+a / 2 r_{p}$ is the empirical parameter. The third term of the above equation includes the effect of Brownian motion, particle surface chemistry, and inter-particle interactions. 
$\gamma$ is the ratio of the nanolayer thickness to the original particle radius, which can be obtained by the following equation [37]:

$$
\gamma=1+a / r_{p}
$$

where $a=\sqrt{2 \pi} \sigma$ is the interfacial layer thickness at the surface of spherical microdomains. $\sigma$ is a parameter characterizing the diffuseness of the interfacial boundary, and $\sigma=40 \mathrm{~nm}$ [37].

Moreover, the thermal conductivity of nanofluid for different particle shapes was calculated using the model proposed by R. L. Hamilton et al. [38]:

For the dynamic viscosity of nanofluid with nanoparticles of different sphericity:

$$
\mu_{n f}=1+K \varphi
$$

where $\mu_{n f}$ is the effective viscosity of nanofluid, $K$ is the 2.5 for sphere and 80 for rod, and $\varphi$ is the particle volume fraction.

For the thermal conductivity of nanofluid with nanoparticles of different sphericity [38]:

$$
k_{n f}=k_{b f} \frac{k_{n p}+(n-1) k_{b f}-\left(k_{b f}-k_{n p}\right)(n-1) \varphi}{k_{n p}+(n-1) k_{b f}+\varphi\left(k_{b f}-k_{n p}\right)}
$$

where $k_{n f}$ is the thermal conductivity of the nanofluid, $k_{b f}$ is the thermal conductivity of the base fluid, $k_{p}$ is the thermal conductivity of the nanoparticle, $n=3 / \Psi$ is the empirical shape parameter and $\Psi$ is particle sphericity, and $\Psi=1$ for spherical particles [39] and $\Psi=0.5$ for rod-shaped particles [40].

\subsection{Mesh Topology and Numerical Method}

The computational domain wa smeshed with the unstructured grid using software ICEM. Figure 2 shows the mesh results, and meshes were refined near the inlet and outlet regions. Grid-independent investigation was conducted with different numbers of elements before performing simulations. As shown in Figure 3, once the grid elements exceeded 1,225,754, the outlet temperature of water became stable. Considering the computational efficiency and accuracy, mesh with element numbers of $1,225,754$ was employed for further study. Prior to conducting simulations, a time-step independent study was conducted, and a time step of $0.5 \mathrm{~s}$ was used for further simulation in this study for higher computational efficiency and accuracy.

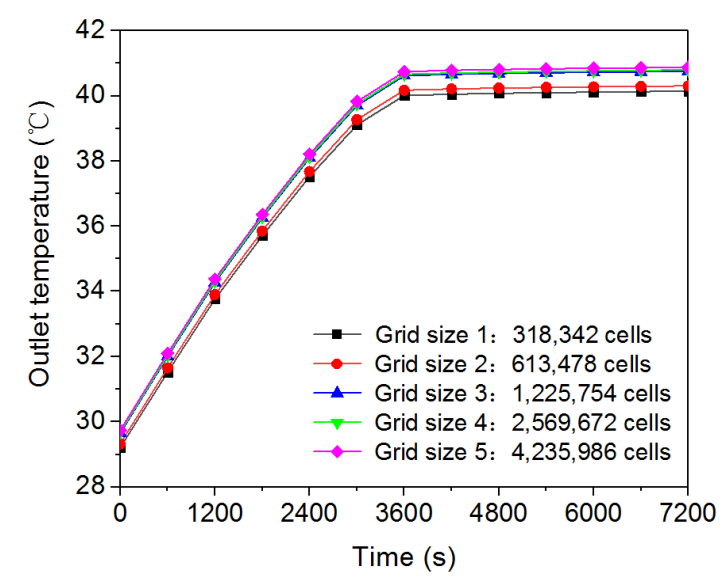

Figure 3. The mesh independence tests for numerical simulation.

\subsection{Numerical Method}

The commercial CFD code ANSYS Fluent-15 was used to solve the governing equations of the numerical models. The Semi-Implicit Method for Pressure-Linked Equations (SIMPLE) algorithm was used to couple pressure and flow rate. The second-order scheme was applied for the pressure 
interpolation. A second-order upwind scheme was adopted for the discretization of the momentum equation, energy equation, turbulent kinetic energy equation, and dissipation rate equation. The heat transfer fluid flow is turbulent flow because the Reynolds number varied between 5335 to 9611 . The standard k model was applied to describe the turbulent flow of heat transfer fluid. The turbulent intensity and hydraulic diameter for the heat transfer fluid inlet were set as $10 \%$ and $0.01 \mathrm{~m}$, respectively. The residual for the convergence target was set as $10^{-7}$ for energy equation and $10^{-3}$ for other equations.

Table 2 shows the operating conditions for different cases. Case 1 was conducted for comparison of experimental and numerical results. Therefore, the inlet flow rate and temperature obtained from the experimental data were inputted into Case 1 through the FLUENT user-defined functions (UDFs). For the Case 2 to 10 , the constant inlet temperature $(305.15 \mathrm{~K})$ and flow rate $(0.707 \mathrm{~m} / \mathrm{s})$ of fluid were chosen according to the weighted average value by time in the experiment. There were 10 cases that were simulated. In Case 3 to 8, the particle diameter was $5 \mathrm{~nm}, 10 \mathrm{~nm}, 20 \mathrm{~nm}, 30 \mathrm{~nm}, 40 \mathrm{~nm}$, and $50 \mathrm{~nm}$, respectively. Murshed's model is valid for the spherical particles. Therefore, the particle shape in Case 3 to 8 was spherical. In Case 9 and 10, the shape of nanoparticles was sphere and rod, respectively. The optimum particle diameter found in Section 3.1 was $40 \mathrm{~nm}$. Therefore, the particle diameter in Case 9 and 10 was $40 \mathrm{~nm}$. A variety of thermophysical properties of nanofluid were calculated for different cases and introduced into cases. The initial ground temperature was $23.15^{\circ} \mathrm{C}$.

Table 2. Operating conditions for different cases.

\begin{tabular}{cccc}
\hline Operating Condition & Particle Diameter $(\mathbf{n m})$ & Particle Shape & Fluid \\
\hline Case 1 & 23.26 & Sphere & Nanofuid \\
Case 2 & $\backslash$ & $\backslash$ & Water \\
Case 3 & 5 & Sphere & Nanofuid \\
Case 4 & 10 & Sphere & Nanofuid \\
Case 5 & 20 & Sphere & Nanofuid \\
Case 6 & 30 & Sphere & Nanofuid \\
Case 7 & 40 & Sphere & Nanofuid \\
Case 8 & 50 & Sphere & Nanofuid \\
Case 9 & 40 & Sphere & Nanofuid \\
Case 10 & 40 & Rod-shaped & Nanofuid \\
\hline
\end{tabular}

Furthermore, the following assumptions were made in the present simulation:

- The fluid temperature in the whole heat transfer process varied from 22 to $40^{\circ} \mathrm{C}$. The thermophysical properties had only little change (less than $5 \%$ ). Therefore, the thermophysical properties of materials were set as constant, and the corresponding temperature was the weighted average value by time.

- The sandbox wall, which was considered as the far-field boundary, was set as adiabatic.

- The initial temperature $\left(23.15^{\circ} \mathrm{C}\right)$ of the ground was constant and uniform.

- The thermal resistance of the heat exchanger tube wall was negligible.

- The sand was assumed to be the uniform material with the homogeneous thermal properties.

\subsection{Validation of Model}

To validate the numerical model, an experimental system was constructed in Chongqing, China. The schematic and photos of the experimental setup are shown in Figures 4 and 5. The experimental apparatus mainly consisted of two center-symmetric GHEs, two flowmeters, two liquid storage tanks with electrical heats, two pumps, a sandbox $(0.8 \mathrm{~m} \times 0.5 \mathrm{~m} \times 0.58 \mathrm{~m})$, and connecting pipes. The inner diameter of the tube was $0.01 \mathrm{~m}$, and the thickness of the tube was $0.001 \mathrm{~m}$. The GHEs were buried in the sand directly. The 50-mm-thick thermal insulation material (polystyrene) was used to wrap the whole tanks, box, and pipes to reduce the heat loss of nanofluid and water. The nanofluid (in \#1 heat exchanger) and water (in \#2 heat exchanger) were pumped into the GHEs before returning to the tanks. 
The flow rate was controlled at $0.707 \mathrm{~m} / \mathrm{s}$ using adjust valves, and the constant heat load ( $50 \mathrm{~W}$ for the power of electrical heater) was inputted into the fluid using electrical heat. The time of the experiment was $2 \mathrm{~h}$.

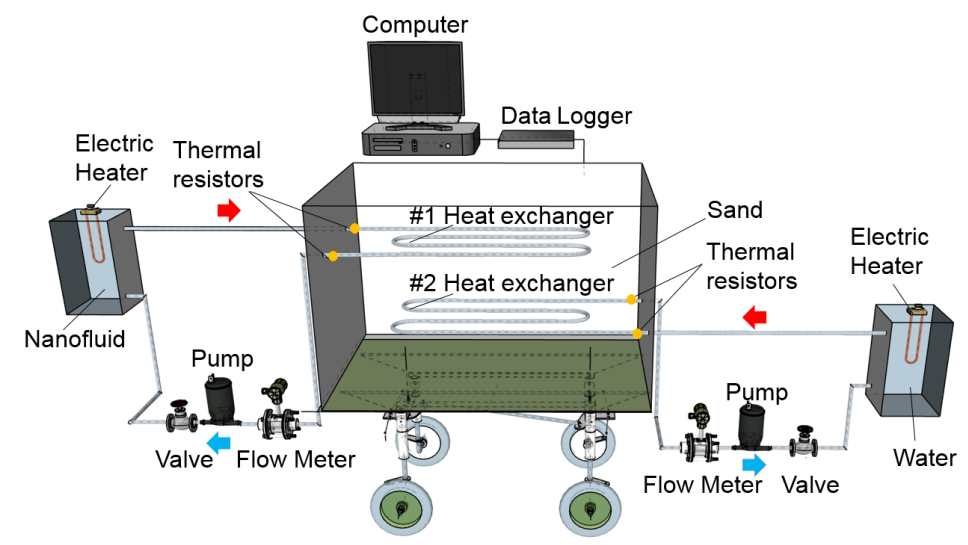

Figure 4. Schematic diagram of the experimental system.

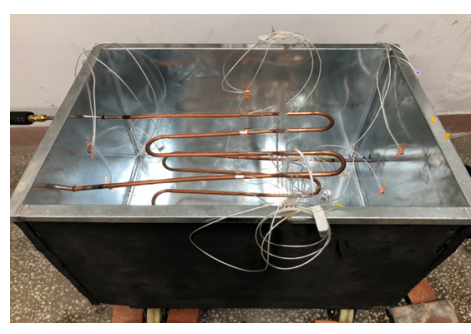

(a)

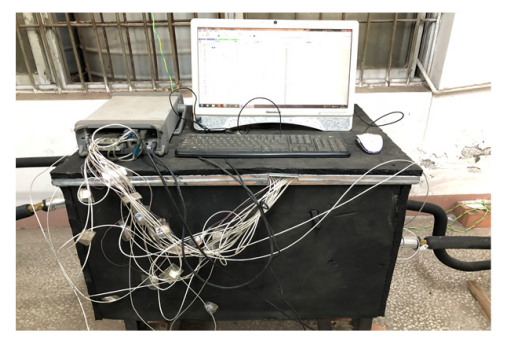

(c)

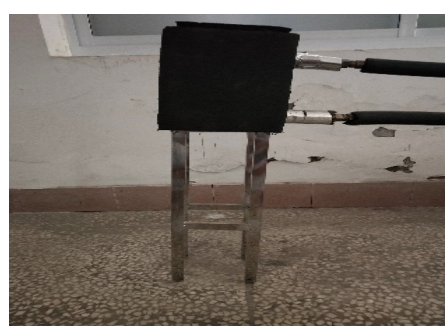

(b)

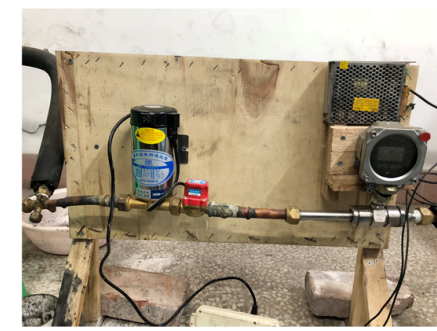

(d)

Figure 5. Photos diagram of the experimental system: (a) Thermal resistors; (b) Nanofluid tank and water tank; (c) Sankbox, computer and data logger and (d) Pump and flow meter.

Four platinum thermal resistors were installed at the inlet and outlet of two GHEs to obtain the inlet and outlet temperature of fluids. The four same platinum thermal resistors were pre-calibrated, and the test error of platinum thermal resistors was $\pm 0.15^{\circ} \mathrm{C}$. According to the guide provided by International Organization for Standardization (ISO) [41], when there is no specific knowledge about the possible values of test results within the interval $E-$ to $E+$, it is reasonable to assume that it is equally probable for test results to lie anywhere within it. Therefore, when the bound is donated by \pm $E$, the uncertainty of the test results can be calculated by:

$$
U=\frac{E}{\sqrt{3}}
$$

where $U$ is the uncertainty, and $E$ is the test error. Therefore, the uncertainty of thermal resistors was \pm $0.087^{\circ} \mathrm{C}$. All thermal resistors were connected to the data logger system. The measuring range, the 
maximum relative error and the relative uncertainty of flow meters was $0.04-0.4 \mathrm{~m}^{3} / \mathrm{h}, 2 \%$, and $\pm 0.2 \%$, respectively. The maximum relative error of the flowmeter was $0.67 \%$.

The inlet temperature and flow rate data of nanofluid obtained in the experiment were introduced into the numerical model using the user-defined functions (Case 1). In the first $40 \mathrm{~min}$, the outlet temperature of nanofluid and the heat transfer process were in an unsteady state. The tube wall and sand in the experiment had worse contact than that in the simulation due to the porosity of experimental sand. As a result, there was less heat released into the ground and higher output temperature in the experiment than that in the simulation. After $40 \mathrm{~min}$, as the nanofluid temperature increased, nanoparticles had more intensified chaotic motion in the experiment, while the single-phase simulation neglected the nanoparticle motion and handled the thermal conductivity of nanofluid as a constant value. The higher nanofluid temperature and more intensified motion mean higher heat transfer rates of nanofluid [42]. Therefore, there was more heat released into the ground and lower outlet temperature in the experiment than that in the simulation. The outlet temperature of nanofluid in the simulation results had a good agreement with that in experiment data, and the maximum deviation was only around $4.47 \%$ (Figure 6).

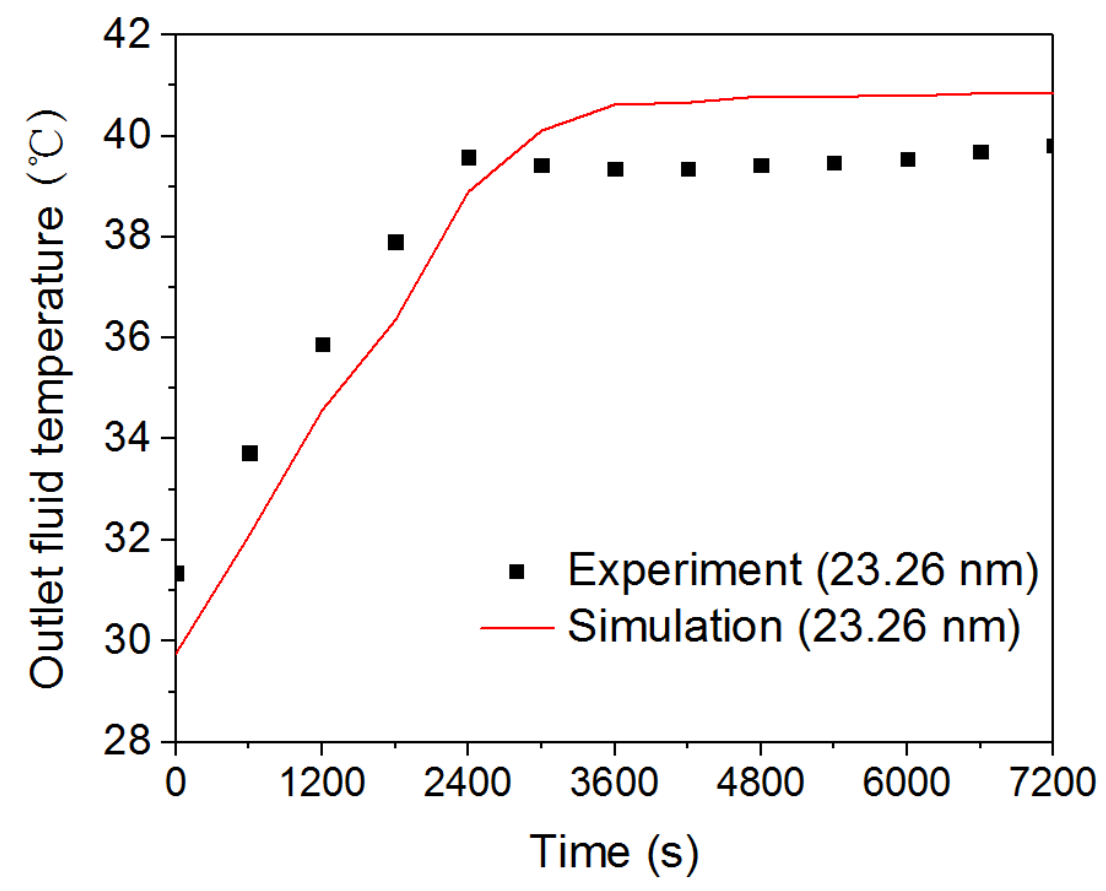

Figure 6. Comparisons of the outlet fluid temperature in experiment and simulation.

\section{Results and Discussion}

\subsection{Effect of Nanoparticle Diameter}

This section investigates the effect of nanoparticle diameter on the overall performance of GHEs in different cases. The heat transfer rate can be calculated by [43]:

$$
Q=m C_{p f}\left(T_{\text {inlet }}-T_{\text {outlet }}\right)
$$

Where $m$ is the mass flow rate of the fluid, $C_{p f}$ is the specific heat of the fluid, $T_{\text {inlet }}$ is the inlet temperatures of the fluid, and $T_{\text {outlet }}$ is the outlet temperatures of the fluid.

The total pressure drop, which is proportional to the energy consumption of the pump, was obtained by [43]:

$$
\Delta P_{T}=P_{\text {Tinlet }}-P_{\text {Toutlet }},
$$


where $\Delta P_{T}$ is the total pressure drop of the fluid, $P_{\text {Tinlet }}$ is inlet total pressure of the fluid, and $P_{\text {Toutlet }}$ is the outlet total pressure of the fluid. In the whole heat transfer process, the variation of total pressure drop is negligible (lower than $5 \%$ ). The average total pressure drop by time in the steady state was selected for further studies.

The performance efficiency coefficient (PEC) was used to evaluate the energy efficiency of nanofluid, in comparison to water and can be obtained by [43]:

$$
P E C=\frac{Q_{n f} / Q_{b f}}{\Delta P_{T b f} / \Delta P_{T n f}},
$$

where PEC is the performance efficiency coefficient, $Q_{n f}$ is the heat transfer of nanofluid, $Q_{b f}$ is the heat transfer of water, $\Delta P_{T n f}$ is the total pressure drop of nanofluid, and $\Delta P_{T b f}$ is the total pressure drop of water. The pressure drop and heat transfer rate for pure water can be calculated according to the numerical result of Case 2.

Figure 7 illustrates the total pressure drop of nanofluid for Case 3 to 8 . For the same particle volume concentration, the smaller particle diameter caused higher viscosity [44] and higher pressure drop. It is noted that the downward trend of pressure drop became gentle when the particle diameter increased.

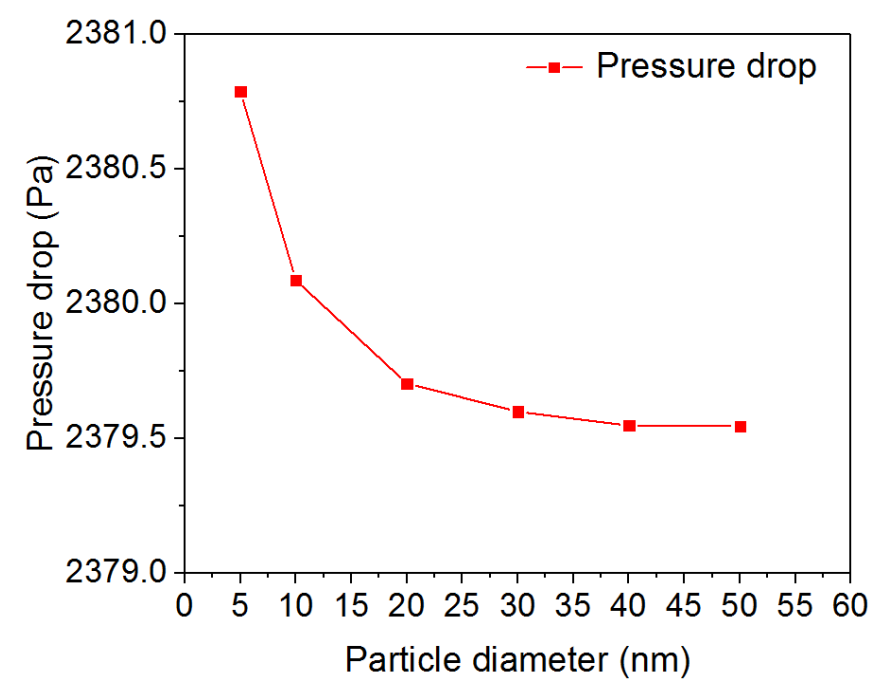

Figure 7. The average total pressure drop for different particle diameters.

The heat transfer process of fluid in the GHEs includes the heat conduction between different parts of fluid, the heat conduction between fluid and tube wall, as well as the thermal convection between different parts of fluids. The thermal conduction of nanofluid strongly depends on the motion of nanoparticles with a higher thermal conductivity than that of base fluid such as water. The higher nanoparticle-to-nanoparticle collision frequency may contribute to the higher effective thermal conductivity of nanofluid [44]. Meanwhile, for the thermal convection, the thicker thermal boundary layers may affect the thermal convection of fluid. For the nanoparticles of smaller diameter, the Brownian force and other two-phase interaction have a more obvious effect on the particle motion, and the chaotic motion of nanoparticles is more intense [45]. As a result, the particle-to-particle collision frequency becomes higher, and there is a higher effective thermal conductivity of nanofluid [44]. However, the smaller particle diameter also leads to higher viscosity of nanofluid [44], which may promote the formation of the thermal boundary layers and affect the thermal convection as well as the convection heat transfer coefficient of nanofluid.

Figure 8 shows the heat transfer rate of nanofluid in Case 3 to 8 . For the nanofluid with $5 \mathrm{~nm}$ nanoparticles, the disadvantage caused by the higher viscosity overcame the advantage brought by the higher thermal conductivity, and the heat transfer rate stabled at $63.53006 \mathrm{~W}$, which was lower 
than that of $10 \mathrm{~nm}, 20 \mathrm{~nm}, 30 \mathrm{~nm}$, and $40 \mathrm{~nm}$. When the particle diameter increased from 5 to $40 \mathrm{~nm}$, the disadvantage caused by higher viscosity dominated the heat transfer capacity of nanofluid, and the $40 \mathrm{~nm}$ owned the highest heat transfer rate $(88.19143 \mathrm{~W})$ followed by $30 \mathrm{~nm}(88.18267 \mathrm{~W}), 20 \mathrm{~nm}$ $(88.17666 \mathrm{~W}), 10 \mathrm{~nm}(88.16871 \mathrm{~W})$, and $5 \mathrm{~nm}(63.53006 \mathrm{~W})$. For the nanofluid with $50 \mathrm{~nm}$ nanoparticles, the disadvantage caused by the lower thermal conductivity dominated the heat transfer capacity of nanofluid, and the heat transfer rate stabled at $63.52520 \mathrm{~W}$, which was also lower than that of the lower particle diameter.

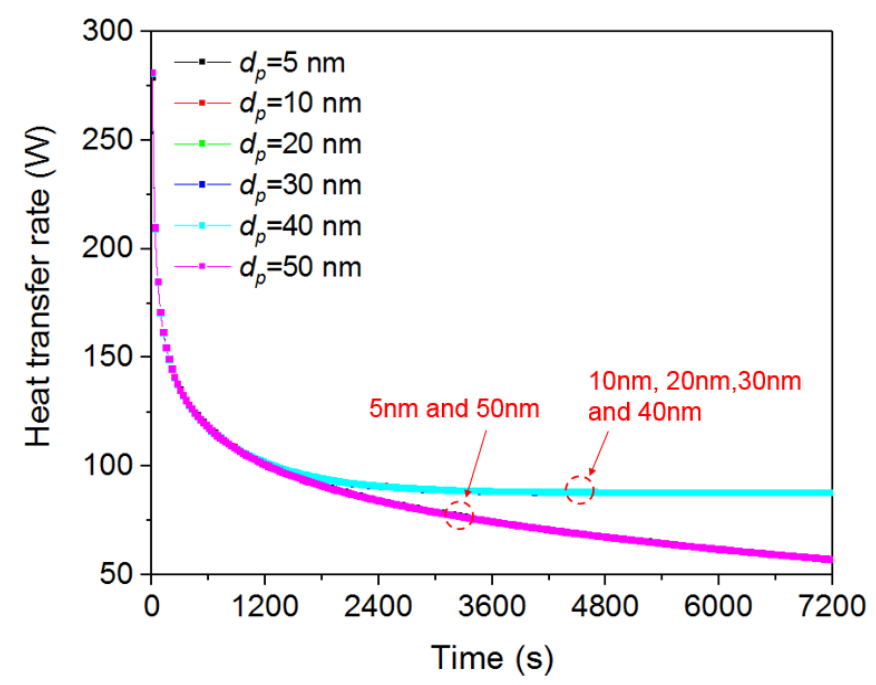

Figure 8. The heat transfer rate for different particle diameters.

The PEC of nanofluid for different particle diameters is shown in Figure 9. For the nanofluid with $5 \mathrm{~nm}$ nanoparticles, even though there was a considerable increase in PEC in the first $300 \mathrm{~s}$ due to the higher thermal conductivity, the PEC slumped and was lower than 1 after $1100 \mathrm{~s}$ due to the higher viscosity. Moreover, for the nanofluid with $50 \mathrm{~nm}$ nanoparticles, the PEC slumped and was lower than 1 after $1080 \mathrm{~s}$ due to the lower thermal conductivity. That means the nanofluids with $5 \mathrm{~nm}$ or $50 \mathrm{~nm}$ nanoparticles had lower energy efficiency than pure water. However, the initial cost of nanofluids was higher than that of traditional circuit fluid (water). Therefore, these two sizes of nanoparticles were not a reasonable choice for nanofluids used in GHEs, and the option of nanoparticle diameter plays an important role in the application of nanofluids in GHEs.

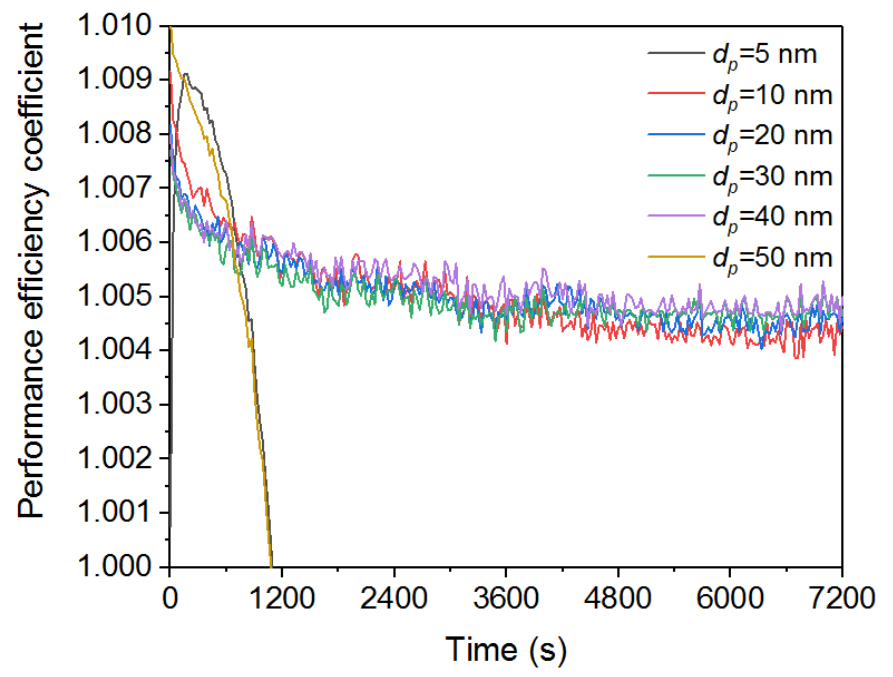

Figure 9. The performance efficiency coefficient for different particle diameters. 
In the first $4800 \mathrm{~s}$, when the heat transfer process was in the unsteady state, the main factors that dominated the heat transfer rate of nanofluid and the energy efficiency of systems were the thermal conductivity and thermal resistance of borehole. The lower nanoparticle diameter that owned the higher thermal conductivity had a higher PEC. Therefore, the $10 \mathrm{~nm}$ nanoparticle had the highest PEC followed by $20 \mathrm{~nm}, 30 \mathrm{~nm}$, and $40 \mathrm{~nm}$.

After $4800 \mathrm{~s}$, when the heat transfer process was in the steady state, more heat had been accumulated in the ground and the heat balance achieved. The main factor that dominated the heat transfer rate of nanofluid and the energy efficiency of systems was the viscosity of nanofluid. The higher nanoparticle diameter that owned the lower viscosity had the higher PEC. Therefore, the $40 \mathrm{~nm}$ nanoparticle had the highest average PEC (1.004875) followed by $30 \mathrm{~nm}$ (1.004719), $20 \mathrm{~nm}$ (1.004639), $10 \mathrm{~nm}$ (1.004389), $5 \mathrm{~nm}(0.7405)$, and $50 \mathrm{~nm}$ (0.7401). Considering the long-running mode of GSHP systems, the $40 \mathrm{~nm}$ was selected as the optimum nanoparticle diameter.

\subsection{Effect of Nanoparticle Phericity}

In this section, Case 9 and 10 were operated to investigate the effect of particle sphericity on the thermal performance of GHEs. The total pressure drop of the fluid can be obtained by Equation (12). Some previous literature [46] has shown that the spherical particle-based nanofluid has lower viscosity compared to rod-shaped particle-based nanofluid. Therefore, the spherical particles had a $7.5 \%$ lower average total pressure drop (2533.78 Pa for spherical particles and 2738.31 Pa for rod-shaped particles) than that of the rod-shaped particles.

The previous literature [46] has shown that nanoparticles with lower sphericity such as rod-shaped particles $(\Psi=0.5)$ may contribute to the higher effective thermal conductivity of nanofluid, in comparison to particles with higher sphericity such as spherical particles $(\Psi=1)$. That means the rod-shaped particle based nanofluid may have more efficient thermal conduction than that of spherical particle-based nanofluid in the tubes. However, the heat transfer process of nanofluid in the tube consists of not only the thermal conduction but also the thermal convection, which has direct relevance to the thickness of thermal boundary layers. The particles with the lower sphericity may cause higher viscosity of the nanofluid [46], in comparison to particles with higher sphericity, which may promote the formation of thermal boundary layers and affect the thermal convection as well as the convection heat transfer coefficient of nanofluid.

The results in the present simulation have shown that the average heat transfer rate of nanofluid with spherical particles was $0.19 \%(79.109 \mathrm{~W}$ for spherical particles and $78.957 \mathrm{~W}$ for rod-shaped particles), higher than that of rod-shaped particles (Figure 10). It can be explained that the disadvantage brought by the thermal boundary layers overcame the advantage brought by the higher thermal conductivity, and the rod-shaped particle owned the relatively low heat transfer capability.

The effect of different nanoparticle sphericity on the energy efficiency of nanofluid in the GHEs was compared using the following energy efficiency ratio [43]:

$$
\frac{\eta_{1}}{\eta_{0.5}}=\frac{Q_{\text {sphere }} / Q_{\text {rod }}}{\Delta P_{\text {rod }} / \Delta P_{\text {sphere }}}
$$

where $\eta_{1}$ and $\eta_{0.5}$ are the heat load-to-pumping power ratio of nanofluid with nanoparticle sphericity of 1 and 0.5 , respectively. $Q_{\text {sphere }}$ is the heat transfer of spherical particle-based nanofluid, $Q_{\text {rod }}$ is the heat transfer of rod-shaped nanoparticle-based nanofluid, $\Delta P_{T \text {,sphere }}$ is the total pressure drop of spherical nanoparticle-based nanofluid, and $\Delta P_{T, r o d}$ is the total pressure drop of rod-shaped nanoparticle-based nanofluid.

The nanoparticles with lower sphericity had higher viscosity, which caused the lower heat transfer rate and the higher total pressure drop. Therefore, as shown in Figure 11, the particle with the higher sphericity ( $\Psi=1$, spherical particle) had an up to $8.55 \%$ higher energy efficiency than that of the particle with the lower sphericity ( $\Psi=0.5$, rod-shaped particles). 


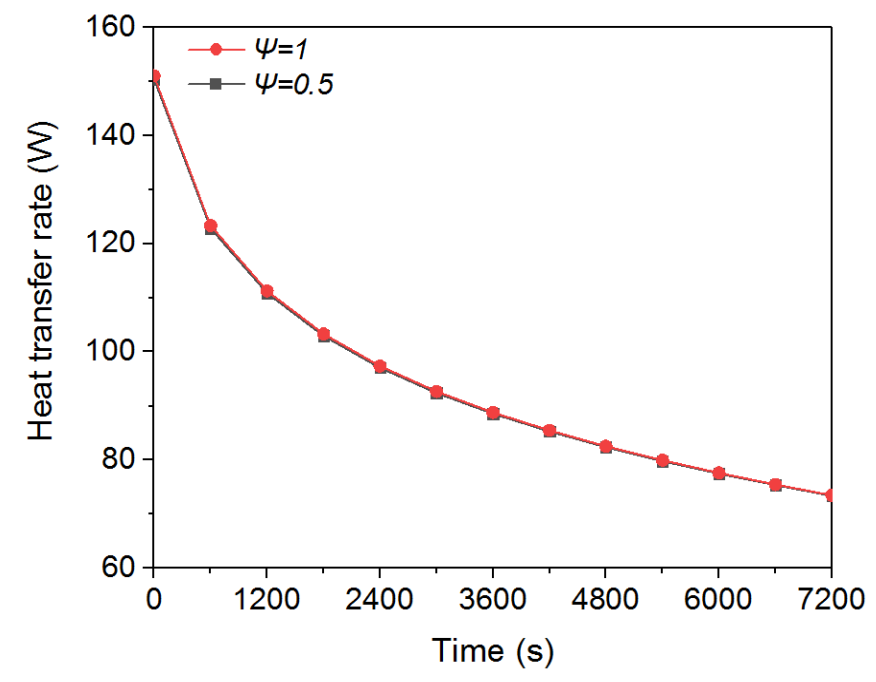

Figure 10. The heat transfer rate for different particle sphericity.

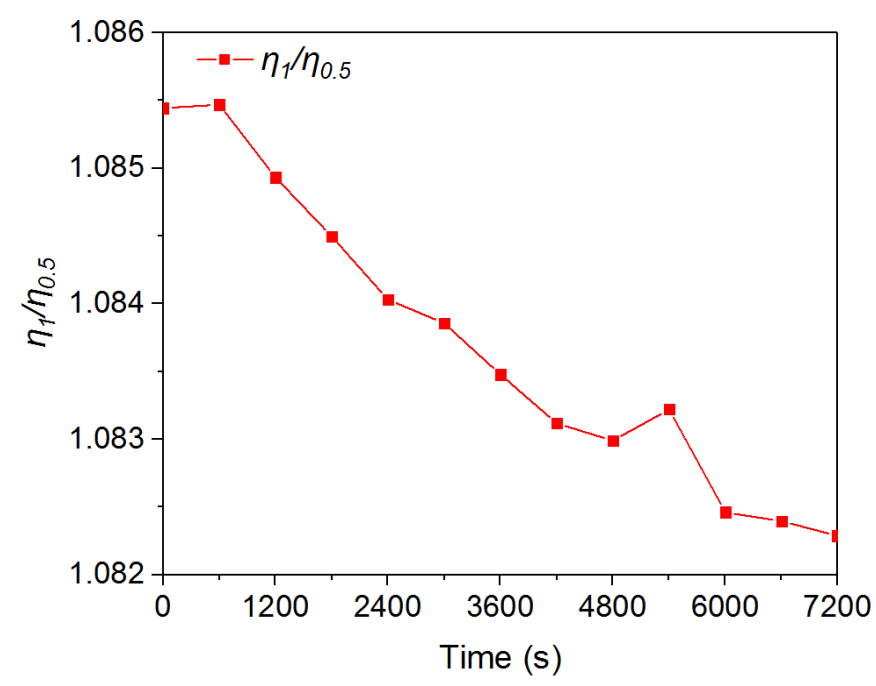

Figure 11. The energy efficiency ratio for different particle sphericity.

\section{Conclusions}

The behaviors of total pressure drop, heat transfer rate, and PEC were numerically investigated for different nanofluids for six different nanoparticle diameters $(5 \mathrm{~nm}, 10 \mathrm{~nm}, 20 \mathrm{~nm}, 30 \mathrm{~nm}, 40 \mathrm{~nm}$, and $50 \mathrm{~nm}$ ) and two different shapes (spherical and rod). The results indicated that the PEC value increased by $35.71 \%$ (from 0.7405 to 1.0049 ) when the particle diameter increased from 5 to $40 \mathrm{~nm}$ and decreased by $26.28 \%$ (from 1.0049 to 0.7401 ) when the particle diameter increased from 40 to $50 \mathrm{~nm}$. Considering the higher initial cost of nanofluid than that of traditional circuit fluid and the PEC lower than 1, the nanoparticles with diameters of $5 \mathrm{~nm}$ and $50 \mathrm{~nm}$ were not recommended for nanofluid used in the GHEs due to the lower energy efficiency than that of pure water. Moreover, when the heat transfer process entered the steady state, the best particle diameter was $40 \mathrm{~nm}$, which owned the highest PEC (1.0049). Furthermore, the spherical nanoparticle owned an up to $8.55 \%$ higher energy efficiency than that of rod-shaped nanoparticles due to the thinner thermal boundary layer. Therefore, the nanoparticle with higher sphericity was suggested to be a more suitable option for nanofluid used in the GHE, in comparison to rod-shaped nanoparticles.

As far as is known, this study is the first study to use the numerical model based on the experiment system to investigate the effect of nanofluid on the thermal performance of GHE. Furthermore, the results showed that the viscosity of nanofluid was an important factor that affected the thermal 
performance of GHE. The previous efforts indicated that the lower particle diameter was characterized by the higher heat transfer rate of GHE. However, the present study found a decrease of $26.02 \%$ in the heat transfer rate of GHE when the particle diameter varied from $40 \mathrm{~nm}$ to $5 \mathrm{~nm}$ due to the higher viscosity of nanofluid with smaller size particles. Meanwhile, in the previous literature, the spherical particle was characterized by the lower heat transfer rate than that of the rod-shaped particle. In this study, the spherical particle was characterized by the $0.19 \%$ higher heat transfer rate of GHEs than that of rod-shaped particles due to the lower viscosity of nanofluid. That means the selections of optimum nanoparticle diameter and shape were different in the different heat exchangers, which can contribute to the application of nanofluid in other types of heat exchangers.

The present study only focused on the sphere and rod-shaped nanoparticles because Hamilton's model was only validated by experimental data for these two shapes. Further refined studies on the thermal performance of nanofluids with other shapes of nanoparticles are warranted.

Author Contributions: All authors conceived and designed the experiments; Performing the simulation \& analyzing the data; Writing, R.D. All authors have read and agreed to the published version of the manuscript.

Funding: This work was supported by the Science and Technology Ministry of China funded National Key R\&D Programmes Intergovernmental International STI Cooperation Key Project (SQ2019YFE011560) and the National Nature Science Foundation of China (Grant Nos. 51576023 and 9164310).

Conflicts of Interest: The authors declare that the research was conducted in the absence of any commercial or financial relationships that could be construed as a potential conflict of interest.

\section{Nomenclature}

$a$

$C_{P}$

$d_{s}$

E

$G_{T}$

$g$

$k$

$k_{B}$

$n$

$p$

$Q$

$r$

$T$

$t$

U

$u$

$x$

$y$

$z$

Greek Letter

$\rho$

$\eta$

$\mu$

$\gamma=1+a / r_{p}$

$\gamma_{1}=1+2 a / r_{p}$

$\omega$

$\Lambda$

$\varphi$

$\Psi$

$\sigma$ interfacial layer thickness at the surface of spherical micro-do-mains (m)

specific heat $(\mathrm{J} / \mathrm{kg} \bullet \mathrm{K})$

distance between two particles (m)

test error $(\%)$

total interparticle potential (\%)

gravitational acceleration $\left(\mathrm{m} / \mathrm{s}^{2}\right)$

thermal conductivity $(\mathrm{W} / \mathrm{m} \bullet \mathrm{K})$

Boltzmann's constant $(\mathrm{J} / \mathrm{K})$

the empirical shape parameter

pressure $(\mathrm{Pa})$

heat transfer rate $(\mathrm{W})$

radius $(\mathrm{m})$

temperature $(\mathrm{K})$

time (s)

uncertainty (\%)

flow rate $(\mathrm{m} / \mathrm{s})$

$\mathrm{x}$-axis coordinates $(\mathrm{m})$

$\mathrm{y}$-axis coordinates $(\mathrm{m})$

$\mathrm{z}$-axis coordinates (m)

$\operatorname{density}\left(\mathrm{kg} / \mathrm{m}^{3}\right)$

heat load-to-pumping power ratio of fluid (\%)

dynamic viscosity, $\left(\mathrm{N} \bullet \mathrm{s} / \mathrm{m}^{2}\right)$

the ratio of the nanolayer thickness to the original particle radius (\%)

empirical parameter $(\%)$

empirical parameter

empirical parameter

the volume fraction of nanoparticle (\%)

sphericity

a parameter characterizing the diffuseness of the interfacial boundary $(\mathrm{m})$ 


$\begin{array}{ll}\text { Subscripts } & \\ c p & \text { complex particle } \\ b f & \text { base fluid } \\ f & \text { fluid } \\ n f & \text { nanofluid } \\ p & \text { particle } \\ s & \text { nanoparticle }\end{array}$

\section{References}

1. Lund, J.W.; Boyd, T.L. Direct utilization of geothermal energy 2015 worldwide review. Geothermics 2016, 60, 66-93. [CrossRef]

2. Han, C.; Yu, X. Sensitivity analysis of a vertical geothermal heat pump system. Appl. Energy 2016, 170, 148-160. [CrossRef]

3. Faizal, M.; Bouazza, A.; Rao, M.S. Heat transfer enhancement of geothermal energy piles. Renew. Sustain. Energy Rev. 2016, 57, 16-33. [CrossRef]

4. Kumar, V.; Tiwari, A.K.; Ghosh, S.K. Application of nanofluids in plate heat exchanger: A review. Energy Convers. Manag. 2015, 105, 1017-1036. [CrossRef]

5. Wilk, J.; Smusz, R.; Grosicki, S. Thermophysical properties of water based Cu nanofluid used in special type of coil heat exchanger. Appl. Therm. Eng. 2017, 127, 933-943. [CrossRef]

6. Nasir, F.M.; Mohamad, A.Y. Heat transfer of $\mathrm{CuO}$-water based nanofluids in a compact heat exchanger. ARPN J. Eng. Appl. Sci. 2006, 11, 2517-2523.

7. Said, Z.; Rahman, S.M.A.; El Haj Assad, M.; Alami, A.H. Heat transfer enhancement and life cycle analysis of a Shell-and-Tube Heat Exchanger using stable CuO/water nanofluid. Sustain. Energy Technol. Assess. 2019, 31, 306-317. [CrossRef]

8. Karuppasamy, M.; Saravanan, R.; Chandrasekaran, M.; Muthuraman, V. Numerical exploration of heat transfer in a heat exchanger tube with cone shape inserts and $\mathrm{Al}_{2} \mathrm{O}_{3}$ and $\mathrm{CuO}$ nanofluids. Mater. Today Proc. 2020, 21, 940-947. [CrossRef]

9. Nageswara Rao, V.; Ravi Sankar, B. Heat transfer and friction factor investigations of $\mathrm{CuO}$ nanofluid flow in a double pipe U-bend heat exchanger. Mater. Today Proc. 2019, 18, 207-218. [CrossRef]

10. Narei, H.; Ghasempour, R.; Noorollahi, Y. The effect of employing nanofluid on reducing the bore length of a vertical ground-source heat pump. Energy Convers. Manag. 2016, 123, 581-591. [CrossRef]

11. Diglio, G.; Roselli, C.; Sasso, M.; Jawali Channabasappa, U. Borehole heat exchanger with nanofluids as heat carrier. Geothermics 2018, 72, 112-123. [CrossRef]

12. Sui, D.; Langåker, V.H.; Yu, Z. Investigation of Thermophysical Properties of Nanofluids for Application in Geothermal Energy. Energy Procedia 2017, 105, 5055-5060. [CrossRef]

13. Bobbo, S.; Colla, L.; Barizza, A.; Rossi, S.; Fedele, L. Characterization of Nanofluids Formed by Fumed Al2O3 in Water for Geothermal Applications West Lafayette. Proceeidngs of the International Refrigeration and Air Conditionging Conference, Indiana, IN, USA, 20 December 2016.

14. Daneshipour, M.; Rafee, R. Nanofluids as the circuit fluids of the geothermal borehole heat exchangers. Int. Commun. Heat Mass Transf. 2017, 81, 34-41. [CrossRef]

15. Baran, A.; Mateescu, T.; Luciu, R. Numerical Simulation of a Heat Exchanger Using $\mathrm{Al}_{2} \mathrm{O}_{3}$ Nanofluid and STES. In Proceedings of the IOP Conference Series: Materials Science and Engineering, Iasi, Rome, 30-31 May 2019; IOP Publishing: Bristol, UK; p. 012040.

16. Kapıcıoğlu, A.; Esen, H. Experimental investigation on using $\mathrm{Al}_{2} \mathrm{O}_{3}$ /ethylene glycol-water nano-fluid in different types of horizontal ground heat exchangers. Appl. Thermal Eng. 2020, 165, 114559. [CrossRef]

17. Khan, A.I.; Valan Arasu, A. A review of influence of nanoparticle synthesis and geometrical parameters on thermophysical properties and stability of nanofluids. Thermal Sci. Eng. Progress 2019, 11, 334-364. [CrossRef]

18. Jamshidi, N.; Mosaffa, A. Investigating the effects of geometric parameters on finned conical helical geothermal heat exchanger and its energy extraction capability. Geothermics 2018, 76, 177-189. [CrossRef] 
19. Elias, M.; Miqdad, M.; Mahbubul, I.; Saidur, R.; Kamalisarvestani, M.; Sohel, M.; Hepbasli, A.; Rahim, N.; Amalina, M. Effect of nanoparticle shape on the heat transfer and thermodynamic performance of a shell and tube heat exchanger. Int. Commun. Heat Mass Transf. 2013, 44, 93-99. [CrossRef]

20. Vanaki, S.M.; Mohammed, H.; Abdollahi, A.; Wahid, M. Effect of nanoparticle shapes on the heat transfer enhancement in a wavy channel with different phase shifts. J. Mol. Liq. 2014, 196, 32-42. [CrossRef]

21. Mahian, O.; Kianifar, A.; Heris, S.Z.; Wongwises, S. First and second laws analysis of a minichannel-based solar collector using boehmite alumina nanofluids: Effects of nanoparticle shape and tube materials. Int. J. Heat Mass Transf. 2014, 78, 1166-1176. [CrossRef]

22. Abbasian Arani, A.A.; Amani, J. Experimental investigation of diameter effect on heat transfer performance and pressure drop of TiO2-water nanofluid. Exp. Thermal Fluid Sci. 2013, 44, 520-533. [CrossRef]

23. Anoop, K.; Sundararajan, T.; Das, S.K. Effect of particle size on the convective heat transfer in nanofluid in the developing region. Int. J. Heat Mass Transf. 2009, 52, 2189-2195. [CrossRef]

24. Ji, Y.; Ma, H.; Su, F.; Wang, G. Particle size effect on heat transfer performance in an oscillating heat pipe. Exp. Thermal Fluid Sci. 2011, 35, 724-727. [CrossRef]

25. Alsarraf, J.; Moradikazerouni, A.; Shahsavar, A.; Afrand, M.; Salehipour, H.; Tran, M.D. Hydrothermal analysis of turbulent boehmite alumina nanofluid flow with different nanoparticle shapes in a minichannel heat exchanger using two-phase mixture model. Phys. A Stat. Mech. Appl. 2019, 520, 275-288. [CrossRef]

26. Al-Rashed, A.A.A.A.; Ranjbarzadeh, R.; Aghakhani, S.; Soltanimehr, M.; Afrand, M.; Nguyen, T.K. Entropy generation of boehmite alumina nanofluid flow through a minichannel heat exchanger considering nanoparticle shape effect. Phys. A Stat. Mech. Appl. 2019, 521, 724-736. [CrossRef]

27. Bahiraei, M.; Monavari, A.; Moayedi, H. Second law assessment of nanofluid flow in a channel fitted with conical ribs for utilization in solar thermal applications: Effect of nanoparticle shape. Int. J. Heat Mass Transf. 2020, 151, 119387. [CrossRef]

28. Xuan, Y.; Li, Q. Heat transfer enhancement of nanofluids. Int. J. Heat Fluid Flow 2000, 21, 58-64. [CrossRef]

29. Khedkar, R.S.; Sonawane, S.S.; Wasewar, K.L. Influence of $\mathrm{CuO}$ nanoparticles in enhancing the thermal conductivity of water and monoethylene glycol based nanofluids. Int. Commun. Heat Mass Transf. 2012, 39, 665-669. [CrossRef]

30. Eastman, J.A.; Choi, U.; Li, S.; Thompson, L.; Lee, S. Enhanced thermal conductivity through the development of nanofluids. MRS Online Proc. Libr. Arch. 1996, 457, 3. [CrossRef]

31. Sezer, N.; Atieh, M.A.; Koç, M. A comprehensive review on synthesis, stability, thermophysical properties, and characterization of nanofluids. Powder Technol. 2019, 344, 404-431. [CrossRef]

32. Li, W.; Li, X.; Peng, Y.; Wang, Y.; Tu, J. Experimental and numerical investigations on heat transfer in stratified subsurface materials. Appl. Thermal Eng. 2018, 135, 228-237. [CrossRef]

33. Li, W.; Li, X.; Peng, Y.; Wang, Y.; Tu, J. Experimental and numerical studies on the thermal performance of ground heat exchangers in a layered subsurface with groundwater. Renew. Energy 2020, 147, 620-629. [CrossRef]

34. Jing, L.; Lam, C. Phase change memory. Sci. China 2011, 54, 1061-1072.

35. Sidik, N.A.C.; Yazid, M.N.A.W.M.; Samion, S.; Musa, M.N.; Mamat, R. Latest development on computational approaches for nanofluid flow modeling: Navier-Stokes based multiphase models. Int. Commun. Heat Mass Transf. 2016, 74, 114-124. [CrossRef]

36. Yu, W.; Choi, S.U.S. The role of interfacial layers in the enhanced thermal conductivity of nanofluids: A renovated Hamilton-Crosser model. J. Nanoparticle Res. 2004, 6, 355-361. [CrossRef]

37. Murshed, S.; Leong, K.; Yang, C. A combined model for the effective thermal conductivity of nanofluids. Appl. Thermal Eng. 2009, 29, 2477-2483. [CrossRef]

38. Hamilton, R.L.; Crosser, O.K. Thermal Conductivity of Heterogeneous Two-Component Systems. Ind. Eng. Chem. Fundam. 1962, 1, 187-191. [CrossRef]

39. Ganvir, R.B.; Walke, P.V.; Kriplani, V.M. Heat transfer characteristics in nanofluid-A review. Renew. Sustain. Energy Rev. 2017, 75, 451-460. [CrossRef]

40. Kleinstreuer, C.; Feng, Y. Experimental and theoretical studies of nanofluid thermal conductivity enhancement: A review. Nanoscale Res. Lett. 2011, 6, 229. [CrossRef]

41. ISO, I.; OIML, B. Guide to the Expression of Uncertainty in Measurement. Geneva, Switzerland 1995, 122, $16-17$. 
42. Das, S.K.; Choi, S.U.S.; Patel, H.E. Heat Transfer in Nanofluids-A Review. Heat Transf. Eng. 2006, $27,3-19$. [CrossRef]

43. Kong, M.; Alvarado, J.L.; Thies, C.; Morefield, S.; Marsh, C.P. Field evaluation of microencapsulated phase change material slurry in ground source heat pump systems. Energy 2017, 122, 691-700. [CrossRef]

44. Munyalo, J.M.; Zhang, X. Particle size effect on thermophysical properties of nanofluid and nanofluid based phase change materials: A review. J. Mol. Liq. 2018, 265, 77-87. [CrossRef]

45. Prasher, R.; Phelan, P.E.; Bhattacharya, P. Effect of aggregation kinetics on the thermal conductivity of nanoscale colloidal solutions (nanofluid). Nano Lett. 2006, 6, 1529-1534. [CrossRef] [PubMed]

46. Kole, M.; Dey, T.K. Role of interfacial layer and clustering on the effective thermal conductivity of CuO-gear oil nanofluids. Exp. Thermal Fluid Sci. 2011, 35, 1490-1495. [CrossRef]

(C) 2020 by the authors. Licensee MDPI, Basel, Switzerland. This article is an open access article distributed under the terms and conditions of the Creative Commons Attribution (CC BY) license (http://creativecommons.org/licenses/by/4.0/). 